\title{
PENGARUH PENDAMPINGAN KELUARGA DIABETIK TERHADAP PENURUNAN KADAR GULA DARAH DI PUSKESMAS WONOREJO
}

\author{
1)Eny Widayati, ${ }^{2)}$ Supriadi, ${ }^{3)}$ Rivan Firdaus \\ 1)Mahasiswa Prodi D-IV Keperawatan, 2,3)Jurusan Keperawatan \\ Program Studi D-IV Keperawatan, Jurusan Keperawatan, Poltekkes Kemenkes \\ Kaltim \\ Email : sai sannara27@yahoo.com
}

\begin{abstract}
Background: Diabetes Mellitus is commonly referred to as the silent killer because it can affect all organs of the body and cause various complaints. In general, the diseases that will be generated in the form of serious disorders included in the case of Diabetes Mellitus complications that is, high blood pressure, heart disease, kidney damage, cataracts, severe skin infections, cerebrovascular disease.

Objective: To know the influence of family assistance to the decrease of blood sugar level in Wonorejo Public Health Center 2017.

Method: Approach used pre experiment with pre and post one group design design, the sample in this research is as much as 10 family mentoring. Bivariate test used is paired simple t-test to determine the relationship between variables

Result: The result of statistic test analysis using paired T-Test shows that the blood sugar variable $P$ value is 0.001 , from the result it can be concluded that the average difference in the variable of blood sugar value meaningful between before and after family assistance ( $p$ value \&lt; $A=0.05$ ).

Suggestion: Doctors, nurses and nutrisionists should always provide education and motivation about DM management at home in DM patients.
\end{abstract}

Keywords: Family Support, Blood Sugar Level

\begin{abstract}
ABSTRAK
Pendahuluan: Diabetes Mellitus biasa disebut dengan the silent killer karena penyakit ini dapat mengenai semua organ tubuh dan menimbulkan berbagai macam keluhan. Pada umumnya, penyakit yang akan ditimbulkan berupa gangguan serius yang termasuk dalam kasus komplikasi Diabetes Mellitus yaitu, tekanan darah tinggi, penyakit jantung, kerusakan ginjal, katarak, infeksi kulit berat, penyakit pembuluh darah otak.

Metode: Pendekatan yang digunakan pra eksperiment dengan rancangan pre and post one group design, sampel dalam penelitian ini adalah sebanyak 10 pendampingan keluarga. Uji bivariat yang digunakan yaitu uji paired simple t-test untuk mengetahui hubungan antar variabel

Hasil: Hasil analisis uji statistic menggunakan paired T-Test menunjukkan bahwa pada variabel gula darah nilai $P$ adalah 0.001 , dari hasil tersebut dapat disimpulkan bahwa adanya perbedaan rata-rata pada variabel
\end{abstract}


nilai gula darah yang bermakna antara sebelum dan sesudah pendampingan keluarga ( $p$ value \&lt; $\alpha$ $=0.05)$.

Kesimpulan : Dokter, perawat dan nutrisionist hendaknya selalu memberikan edukasi dan motivasi tentang pengelolaan Diabetes Mellitus di rumah pada penderita Diabetes Mellitus, baik di saat pelayanan di Puskesmas maupun dengan kunjungan rumah melalui kegiatan Perkesmas.

Kata Kunci : Pendampingan Keluarga, Kadar Gula Darah

\section{PENDAHULUAN}

Menurut Badan Kesehatan

Dunia WHO, kematian akibat Penyakit Tidak Menular (PTM) diperkirakan akan terus meningkat di seluruh dunia, peningkatan terbesar akan terjadi di negaranegara menengah dan miskin. Tingkat prevalensi dari diabetes mellitus sangat tinggi, diperkirakan saat ini pada tahun 2012 China telah menggeser posisi India sebagai 'Ibukota Diabetes Mellitus Dunia' dengan jumlah penderita diabetes tercatat mencapai 90 juta orang. Posisi ketiga diduduki oleh Amerika Serikat dengan jumlah penderita lebih dari 23 juta orang. Dari jumlah ini $10 \%$ - $20 \%$ sebagai tipe I dan $80 \%$ - 90\% sebagai tipe II, dimana penderita merasa sehat, tetapi berisiko untuk mengalami interaksi glukosa yang lebih berat (WHO, 2013). Di Kalimantan Timur, penyakit Diabetes Mellitus telah menduduki urutan kelima dari 10 penyakit terbanyak di Provinsi tersebut prevalensi Diabetes Mellitus di Kalimantan Timur adalah sebesar $1,3 \%$ dengan prevalensi tertinggi di Bulungan $1,7 \%$ dan Samarinda $1,6 \%$, menurut karakteristik responden prevalensi
Diabetes Mellitus terbesar pada Usia > 65 tahun 10,8\%. Berdasarkan laporan dari Dinas Kesehatan Provinsi Kalimantan Timur tahun 2016 tercatat pada tahun 2012 Jumlah kasus baru pada penderita Diabetes Mellitus sebanyak 5.098 kasus dan untuk jumlah kasus kematian akibat penyakit Diabetes Mellitus 46 kasus, kemudian pada tahun 2013 meningkat menjadi 6.549 kasus baru dan 30 kasuis kematian. Kemudian pada tahun 2014 meningkat menjadi 24.944 kasus baru dan 73 kasus kematian. Diabetes Melitus di Benua Etam yang menduduki peringkat tertinggi adalah Samarinda dengan 4,1 persen. Sedangkan kasus Diabetes Mellitus dikota Samarinda pada tahun 2015 pada penderita Diabetes Mellitus tipe I ( IDDM) mencatat sebanyak 175 kasus, pada kasus Diabetes Mellitus tipe II ( NIDDM ) mencatatat sebanyak 9.175 kasus, sedangkan pada tahun 2016 dari bulan Januari hingga September menyatkan kasus Diabetes Mellitus tipe II mencatat sebanyak 6.771 kasus. ( Samarinda, 2016)

Angka kejadian Diabetes Mellitus khususnya di Puskesmas 
Wonorejo mengalami peningkatan 20\% dari tahun 2015 ke tahun 2016.

Penderita pada wilayah tersebut sebagian besar berumur 45 keatas. Pada tahun 2015 Diabetes Mellitus tidak masuk 10 besar penyakit, sedangkan di tahun 2016 Diabetes Mellitus masuk dalam urutan ke 8 dalam 10 besar penyakit (Puskesmas Wonorejo, 2016). Berdasarkan hasil wawancara dari staf puskesmas Wonorejo bagian poli Lansia didapatkan informasi bahwa kasus Diabetes Melletus di Puskesmas Wonorejo masih tinggi, salah satu penyebabnya adalah pendampingan keluarga yang masih kurang.

Dari hasil studi pendahuluan yang dilakukan oleh peneliti pada pasien Diabetes Mellitus yang berkunjung ke Puskesmas Wonorejo ditemukan bahwa dari 10 orang pasien Diabetes Mellitus, 6 diantaranya datang sendiri tanpa diantar keluarga, dan dari 6 orang pasien yang tidak didampingi keluarga 5 diantaranya mempunyai hasil GDS masih < 200 mg/dl dan dari 4 pasien yang didampingi keluarga satu diantaranya hasil GDS masih < $200 \mathrm{mg} / \mathrm{dl}$, sehingga peneliti tertarik untuk melakukan pendampingan keluarga dengan penyuluhan keluarga menggunakan media berupa buku saku. Yang dapat di gunakan keluarga untuk bisa pentingnya minum obat dan mengatur diit Diabetes Mellitus. Sehingga angka peningkatan terjadinya Diabetes Mellitus dapat di minimalisir.
Berdasarkan latar belakang diatas, maka penulis tertarik untuk meneliti tentang pengaruh pendampingan keluarga Diabetik terhadap penurunan kadar gula darah di wilayah kerja Puskesmas Wonorejo.

\section{METODE PENELITIAN}

Penelitian ini merupakan penelitian dengan pendekatan praeksperimen yaitu rancangan percobaan tidak murni dengan penelitian uji klinis tetapi melakukan perlakuan tehnik pendampingan keluarga dengan menggunakan media penyuluhan kesehatan berupa buku saku kepada keluarga pasien Diabetes Mellitus untuk panduan perawatan pasien Diabetes Mellitus. Penelitian ini menggunakan rancangan pre dan post one group test design yaitu rancangan perlakuan menggunakan satu kelompok sampel yang sama dengan satu penilaian setelah perlakuan. Menurut Sugiyono (2008), rancangan pre dan post one group test design merupakan pengamatan pada satu kelompok sebelum diberi perlakuan dan sesudah diberi perlakuan.

Populasi dalam penelitian ini adalah seluruh pendamping keluarga penderita Diabetes Mellitus yang ada di poli lansia di wilayah kerja Puskesmas Wonorejo sebanyak 62 orang. Tehnik sampling yang digunakan dalam penelitian ini adalah tehnik purposive sampling, yaitu suatu metode pengambilan sampel yang 
dilakukan berdasarkan maksud dan tujuan tertentu dengan memperhatikan ciri-ciri dan karakteristik populasi. Adapun variabel Independen dalam

\section{HASIL DAN PEMBAHASAN}

Tabel. 1

Karakteristik Responden

Berdasarkan Umur Pendampingan Keluarga Diabetik Di Wilayah Kerja Puskesmas Wonorejo Samarinda

\begin{tabular}{ccc}
\hline \multicolumn{1}{c}{ Umur } & Frekuensi & Persentase $(\%)$ \\
\hline 46-55 tahun & 4 & 40 \\
56-65 tahun & 6 & 60 \\
Jumlah & 10 & 100 \\
\hline
\end{tabular}

Sumber: Data primer, 2017

Tabel diatas menunjukkan bahwa hampir setengahnya responden berumur 46-55 tahun (40\%) dan sebagian besar responden berumur 56-65 tahun (60\%). Pengkategorian umur berdasarkan Depkes (2009) dimana terbanyak pada rentang 5665 termasuk dalam kategori lansia tua.

Tabel 2.

Karakteristik responden berdasarkan Pendampingan Keluarga Diabetik Di Wilayah Kerja Puskesmas Wonorejo Samarinda.

\begin{tabular}{lcc}
\hline Pendidikan & Frekuensi & $\begin{array}{c}\text { Persentase } \\
(\%)\end{array}$ \\
\hline SMA & 6 & 60 \\
D3 & 2 & 20 \\
S1 & 2 & 20 \\
Jumlah & 10 & 100
\end{tabular}

Sumber: Data primer, 2017

Berdasarkan tabel diatas diperoleh hasil bahwa sebagian kecil responden berpendidikan D3 dan S1 $(20 \%)$ dan sebagian besar penelitian ini adalah pendampingan keluarga Diabetik dan variabel dependennya adalah penurunan kadar gula darah.

responden berpendidikan SMA $(60 \%)$.

Tabel 3.

Karakteristik responden berdasarkan Pendampingan Keluarga Diabetik Di Wilayah Kerja Puskesmas Wonorejo Samarinda.

\begin{tabular}{lcc} 
Jenis Kelamin & Frekuensi & $\begin{array}{c}\text { Persentase } \\
(\%)\end{array}$ \\
\hline Laki-laki & 4 & 40 \\
Perempuan & 6 & 60 \\
Jumlah & 10 & 100 \\
\hline
\end{tabular}

Sumber: Data primer, 2017 Berdasarkan tabel diatas diperoleh hasil bahwa hampir setengah responden berjenis kelamin laki-laki $(40 \%)$ dan sebagian besar responden berjenis kelamin perempuan.

Tabel 4.

Gambaran Gula Darah Pasien Diabetik Di Wilayah Kerja Puskesmas Wonorejo

\begin{tabular}{cccccccc}
\hline $\begin{array}{c}\text { Inisial } \\
\text { Pasie } \\
\text { n }\end{array}$ & $\begin{array}{c}\text { Pre } \\
\text { Hari } \\
\text { Ke- } \\
\end{array}$ & $\begin{array}{c}\text { Pre } \\
\text { Hari } \\
\text { Ke- }\end{array}$ & $\begin{array}{c}\text { Pre } \\
\text { Hari } \\
\text { Ke- }\end{array}$ & $\begin{array}{c}\text { Pre } \\
\text { Hari } \\
\text { Ke-4 } \\
(\mathrm{mg} / \mathrm{dl}\end{array}$ & $\begin{array}{c}\text { Pre } \\
\text { Hari } \\
\text { Ke-5 }\end{array}$ & $\begin{array}{c}\text { Pre } \\
\text { Hari } \\
\text { Ke- }\end{array}$ & $\begin{array}{c}\text { Post } \\
\text { Hari } \\
\text { Ke7 }\end{array}$ \\
\hline KS & 267 & 297 & 209 & 274 & 205 & 215 & 156 \\
N & 403 & 190 & 214 & 213 & 171 & 163 & 137 \\
K & 580 & 591 & 563 & 485 & 306 & 270 & 210 \\
D & 284 & 292 & 277 & 247 & 222 & 159 & 139 \\
M & 242 & 207 & 197 & 138 & 144 & 101 & 97 \\
E & 306 & 180 & 178 & 274 & 236 & 120 & 138 \\
R & 233 & 144 & 194 & 138 & 101 & 99 & 207 \\
H & 347 & 339 & 308 & 214 & 195 & 125 & 121 \\
J & 244 & 211 & 218 & 197 & 182 & 144 & 144 \\
T & 425 & 408 & 401 & 359 & 205 & 77 & 148 \\
\hline
\end{tabular}

Sumber: Data primer, 2017 
Berdasarkan tabel diatas diperoleh hasil bahwa seluruh gula darah pada pasien Diabetes Mellius menurun setelah diberikan pendampingan keluarga selama 7 hari.

Tabel 5.

Rata-rata nilai Gula darah responden sebelum dan sesudah perlakuan pada penderita DM di Wilayah Kerja Puskesmas Wonorejo

\begin{tabular}{lllcll}
\hline Variabel & $\begin{array}{l}\text { Pengu } \\
\text { kuran }\end{array}$ & Mean & SD & $\begin{array}{l}\text { in- } \\
\text { Maks }\end{array}$ & $5 \% \mathrm{Cl}$ \\
\hline Gula & Sebelu & 324.7 & 114.216 & $07-$ & $42.99-$ \\
Darah & $\mathrm{m}$ & & & 580 & 406.41 \\
& Sesud & 149.7 & 34.937 & $7-$ & $24.68-$ \\
& ah & & & 210 & 174.72 \\
\hline
\end{tabular}

Samarinda $(n=10)$

Sumber: Data primer, 2017

Tabel di atas menunjukkan bahwa nilai rata-rata gula darah sebelum mendapatkan pendampingan keluarga sebesar 324,7 , nilai standar deviasi sebesar 114,216, dan nilai gula darah minimum sebesar 207 dan nilai ratarata gula darah setelah mendapatkan pendampingan keluarga sebesar 97, nilai standar deviasi 34,937, dan nilai minimum gula darah 97 dan nilai maximum gula darah 210 .

Tabel 6.

Uji Normalitas

\begin{tabular}{|c|c|c|}
\hline Variabel & Pengukuran & Uji normalitas \\
\hline Gula & Sebelum & 0,164 \\
\hline Darah & Sesudah & 0,143 \\
\hline & norma & deng \\
\hline
\end{tabular}
menggunakan uji Shapiro wilk $(n=10)$ didapatkan nilai sebelum perlakuan $\mathrm{p}: \quad 0,164>0,05$ dan sesudah perlakuan $p: 0,143>0,05$ dapat disimpulkan bahwa data keduanya berdistribusi normal.

Tabel 7.

Perbedaan rata-rata gula

darah responden sebelum dan sesudah perlakuan pada penderita Diabetes Mellitus di Wilayah Kerja

Puskesmas Wonorejo Samarinda

\begin{tabular}{lcccccc}
\multicolumn{6}{c}{$(\mathrm{n}=10)$} \\
\hline Variabel & $\begin{array}{c}\text { Pengukur } \\
\text { an }\end{array}$ & $\mathrm{n}$ & Mean & $\begin{array}{c}\text { Beda } \\
\text { Mean }\end{array}$ & $95 \% \mathrm{Cl}$ & $p$ \\
\hline Gula & Sebelum & 10 & 324.7 & 175.0 & $98.244-$ & 0. \\
Darah & Sesudah & 10 & 149.7 & & 251.756 & 00 \\
& & & & & & 1 \\
\hline Sumber:
\end{tabular}

Sumber: Data primer, 2017

Tabel diatas menunjukkan hasil analisis uji statistik bahwa pada variabel gula darah nilai $P$ adalah 0.001, dari hasil tersebut dapat disimpulkan bahwa adanya perbedaan rata-rata pada variabel nilai gula darah yang bermakna antara sebelum dan sesudah pendampingan keluarga ( $p$ value < $\alpha=0.05$ ).

Dari hasil analisis bivariat didapatkan hasil uji statistic menggunakan paired t-test menunjukkan bahwa nilai $P$ adalah 0.001 ,hasil tersebut dapat disimpulkan bahwa adanya perbedaan rata-rata pada variabel nilai gula darah yang bermakna antara sebelum dan sesudah pendampingan keluarga ( $p$ value < $\alpha=0.05)$. Hasil penelitian ini sejalan dengan penelitian yang dilakukan oleh Abdillah (2016) yang berjudul pengaruh pendampingan keluarga terhadap kepatuhan diet pada penderita diabetes mellitus di wilayah Puskesmas Banyuanyar Surakarta yang menyatakan bahwa 
ada pengaruh pendampingan keluarga terhadap diet penderita Diabetes Mellitus dengan nilai $p$ value sebesar 0,009(<0,05).

Menurut Delima (2011) ada pengaruh model pendampingan terhadap terkontrolnya diabetes mellitus pada penderita Diabetes Mellitus. Indriani (2014) ada pengaruh terhadap pendampingan keluarga meningkatkan kepatuhan minum obat. ada hubungan yang signifikan antara peran pendampingan spiritual dengan motivasi kesembuhan pada pasien lanjut usia di Instalasi Rawat Inap Dewasa Rumah Sakit Baptis Kediri. Pendampingan berarti bantuan dari pihak luar, baik perorangan mau kelompok untuk menambahkan kesadaran dalam rangka pemenuhan kebutuhan dan pemecahan permasalahan kelompok. Menururut Lina. M. \& sulityarini. T (2013) pendampingan dapat mempengaruhi kepatuhan karena dalam pendampingan dapat menekan munculnya stres, memberikan informasi yang dapat memotifasi pasien dan keluarga untuk meningkatkan kepatuhan, memberikan dukungan emosional.

Diabetes mellitus umumnya terjadi pada saat pola gaya hidup dan perilaku telah terbentuk dengan kokoh. Keberhasilan pengelolaan Diabetes Mellitus mandiri membutuhkan partisipasi aktif pasien, keluarga, dan masyarakat. Tim kesehatan harus mendampingi pasien menuju perubahan perilaku. Keberhasilan perubahan perilaku, membutuhkan edukasi yang komprehensif, pengembangan keterampilan dan motivasi, Edukasi secara individual atau pendekatan berdasarkan penyelesaian masalah merupakan inti perubahan perilaku yang berhasil. Pendampingan adalah bentuk edukasi, konseling dan motivasi untuk membantu penyelesaian permasalahan yang dihadapi dalam pengelolaan penyakitnya di rumah.

Menurut asumsi peneliti pengelolaan dan pengendalian diri bagi penderita Diabetes Mellitus dilakukan seumur hidup, maka mereka sangat perlu mendapatkan pengetahuan secara terus menerus mengenai pengelolaan diri seharihari, berkesempatan untuk konsultasi tentang masalah yang terkait dengan penyakit yang diderita dan mendapatkan pembenaran dari tindakan-tindakan yang telah dilakukan dalam pengelolaan dirinya, sehingga meningkatkan motivasi dalam melakukan penyenyusaian gaya hidup terkait dengan penyakit Diabetes Mellitus yang diderita.

Pendampingan keluarga merupakan hal yang penting dalam menurunkan gula darah pasien diabetes, hal ini terbukti dalam penelitian ini. Pendampingan keluarga yang selama ini diliat selama meneliti adalah berupa mengatur, merencanakan, menyiapkan, mengingatkan dan mengawasi pola makan anggota keluarganya yang sakit Diabetes Mellitus, dengan cara mengatur, 
mengingatkan jadwal makan, merencanakan dan menyiapkan pendampingan keluarga ( $p$ menu makanan serta mengawasi jumlah porsi dan jenis makanan yang boleh dimakan. Semua ini bisa diteliti apabila ada penerimaan keluarga terhadap peneliti untuk keberhasilan penelitian ini.

\section{SIMPULAN}

1. Karakteristik responden penelitian bahwa responden terbanyak berada pada rentang umur 56-65 tahun yaitu sebanyak 6 orang (60\%), selanjutnya responden terkecil umurnya berada pada rentang 46-55 tahun sebanyak 4 orang (40\%). Responden terbanyak berpendidikan SMA sebanyak 6 orang $(60,0 \%)$, kemudian terkecil sebanyak 2 orang $(20,0 \%)$ berpendidikan D3 dan S1. Responden terbanyak berjenis kelamin perempuan sebanyak 6 orang $(60,0 \%)$ dan terkecil berjenis kelamin lakilaki sebanyak 4 orang (40,0\%).

2. Adanya penurunan rata-rata gula darah antara sebelum dan sesudah dilakukan pemberian pendampingan keluarga.

3. Hasil analisis uji statistic menggunakan paired T-Test menunjukkan bahwa pada variabel gula darah nilai $P$ adalah 0.001, dari hasil tersebut dapat disimpulkan bahwa adanya perbedaan ratarata pada variabel nilai gula darah yang bermakna antara sebelum dan sesudah 